\title{
PEMAHAMAN PERAWAT MENGENAI DIAGNOSA KEPERAWATAN UNTUK MENENTUKAN PERAWATAN YANG DI BUTUHKAN \\ PASIEN
}

Nabila Rahmadhani

\section{Rahmadhaninabila2@gmail.com}

\begin{abstract}
One of the important activities in the nursing process is nursing assessment. Experience shows that often nurses have difficulty determining the specific nursing diagnosis experienced by patients. This may be due to poorly structured nursing assessments. One of the efforts shown by the formulation or enforcement of welfare nursing diagnoses is one form of nursing diagnosis that needs to be developed. The writing of this welfare diagnosis can be done in various health service settings and demands a change in the behavior of nurses from being oriented towards healing efforts to improving the health and welfare of clients.
\end{abstract}

Kaywords: Nursing diagnoses, nursing diagnosis category

\begin{abstract}
Abstrak
Salah satu kegiatan yang penting dalam proses keperawatan adalah pengkajian keperawatan. Pengalaman menunjukkan bahwa sering sekali perawat kesulitan dalam menentukan diagnosis keperawatan spesifik yang dialami oleh pasien.Hal ini mungkin karena pengkajian keperawatan yang tidak terstruktur dengan baik. Salah satu upaya yang ditunjukkan dengan perumusan atau penegakan diagnosa keperawatan sejahtera yang merupakan salah satu bentuk diagnosa keperawatan yang perlu dikembangkan. Penulisan diagnosa sejahtera ini dapat dilakukan di berbagai tatanan pelayanan kesehatan dan menuntut perubahan perilaku perawat dari yang berorientasi pada upaya penyembuhan kepada upaya peningkatan kesehatan dan kesejahteraan klien
\end{abstract}

Kata kunci: Diagnosa keperawatan, kategori diagnosa keperawatan 


\section{Latar belakang}

Salah satu kegiatan yang penting dalam proses keperawatan adalah pengkajian keperawatan. Pengkajian keperawatan ini sangat penting karena dari pengkajian keperawatan maka perawat akan mampu menentukan apa masalahkeperawatan/diganosa keperawatan dan masalah kolaboratif/diagnosis potensial komplikasi yang dialami oleh pasien dan membuat perencanaan dalam merawat pasien.

Pengalaman menunjukkan bahwa sering sekali perawat kesulitan dalam menentukan diagnosis keperawatan spesifik yang dialami oleh pasien.Hal ini mungkin karena pengkajian keperawatan yang tidak terstruktur dengan baik.Pengalaman menunjukkan bahwa pengkajian yang dilakukan oleh perawat tidak mempunyai urutan yang runut dan terkait dengan diagnosis keperawatan.Sering terjadi perawat mempunyai data tertentu tetapi kebingungan untuk menentukan data tersebut mendukung diagnosis keperawatan yang mana. Atau sebaliknya perawat mempunyai prediksi pasien mempunyai diagnosis tertentu tetapi tidak tahu data apa yang perlu dikaji untuk mendukung diagnosis tersebut muncul (Nurjannah, 2010).

Panduan penulisan diagnosis keperawatan NOC, NIC (2011), menyatakan bahwa diagnosis keperawatan yang timbul pada pasien penyakit pernafasan ada beberapa diagnosis, diantaranya bersihan jalan nafas tidak efektif, pola nafas tidak efektif, gangguan pertukaran gas, kurang pengetahuan, resiko aspirasi, dan ketidakseimbangan nutrisi kurang dari kebutuhan tubuh (Herman, 2014 ).

Untuk jumlah diagnosa keperawatan yang muncul pada satu orang pasien rata-rata satu jenis diagnosa keperawatan saja, padahal diagnosa keperawatan bisa ditegakkan berdasarkan respon pasien. Diagnosa keperawatan tunggal, bisa jadi dikarenakan pengkajian yang kurang lengkap, atau bisa dikarenakan ketidaktahuan perawat dalam menentukan diagnosa lain yang sesuai. Pada sisi lain pada diagnosa keperawatan, ditemukan adanya pernyataan nama diagnosa yang berbeda, meskipun respon masalah pasien sebenarnya sama. Jadi disini tidak ada keseragaman bahasa dalam nama diagnosa keperawatan. Sehingga seringnya diagnosa itu ditemukan menjadi hal yang terpenting dalam keperawatan. Perawat dapat mempersiapkan sumber daya untuk mengatasi diagnosa keperawatan tersebut. Rumah sakit juga akan menyiapkan kebutuhan sumber daya yang diperlukan untuk kepentingan diagnosa tersebut.

Penegakan diagnosis merupakan aspek penting dalam praktik keperawatan. Sepanjang waktu, format dan kualitas penegakan diagnosis telah berkembang, tetapi fokusnya terus berdampak 
terhadap perawatan klien (Potter \& Perry; 2009). Sistem penegakan diagnosis yang ideal harus memberikan informasi klien yang komprehensif, menunjukkan hasil dan standar klien, memfasilitasi reimbursement dari pemerintah dan dari perusahaan asuransi pembayar, serta berfungsi sebagai dokumen legal (Twardon dan Gartner, 1993: Potter \& Perry; 2009). Mutu asuhan keperawatan dapat tergambar dari penegakan diagnosis proses keperawatan (Gillies, 1994). Penegakan diagnosis dalam keperawatan memegang peranan penting terhadap segala macam tuntutan masyarakat yang semakin kritis dan mempengaruhi kesadaran masyarakat akan hak-haknya dari suatu unit kesehatan. Pendokumentasian yang tidak dilakukan dengan lengkap dapat menurunkan mutu pelayanan keperawatan karena tidak dapat mengidentifikasi sejauh mana tingkat keberhasilan asuhan keperawatan yang telah diberikan dalam aspek legal perawat tidak mempunyai bukti tertulis jika klien menuntut ketidakpuasan akan pelayanan keperawatan (Nursalam, 2008; Iyer, 2001).

Diagnosis keperawatan merupakan penilaian klinis terhadap pengalaman/respon individu, keluarga, atau komunitas pada masalah kesehatan/risiko masalah kesehatan atau pada proses kehidupan. Diagnosis keperawatan merupakan bagian vital dalam menentukan asuhan keperawatan yang sesuai untuk membantu klien mencapai kesehatan yang optimal. Perawatan yang profesional dicerminkan dalam pendokumentasian yang profesional, yang membuktikan tentang apa yang dilakukan oleh perawat dan secara efektif menggambarkan status dan kemajuan klien. Informasi yang menggambarkan masalah klien atau diagnosis keperawatan kemudian mengarah pada pemberian asuhan keperawatan untuk memilih suatu rencana perawatan yang sesuai dengan terapi keperawatan (Potter \& Perry; 2009).

\section{Metode}

Metode yang di gunakan dalam kajian ini adalah metode literature review, di mana pada kajian ini di buat berdasarkan berbagai suber bacaan yang berupa, buku bacaan, jurnal, tesis juga maupun ebook yang berhubunga dengan diagnosa dalam keperawatan.

Kajian ini juga merupakan kajian bebas diman adalam kajian ini bersifat bebas dimana kajian ini juga di buat dengan cara perbandingan dengan artikel satu dengan artikel arrikel yang lainnya dan menghasilkan perbandingan yang di tulis secara berurutan dan bertauran dalam hasil kajian ini 
Untuk mendapatkan pembahasan sesuai dengan topik, penulisan kajian ini melibatkan banyak media cetak atau pun media online yang membahas maslah sesuai dengan topik yang di kaji di jurnal ini. Untuk media yang di yang di gunakan juga melewati seleksi yang memilih sumber dengan referensi taerbaru.

\section{Hasil}

Hasil dari metode ini yaitu Pemahaman Perawat Mengenai Diagnosa Keperawatan Untuk Menentukan Perawatan yang di Butuhkan Pasien harus di persiapakan atau di rencanakan secara matang agar mendapatkan hasil yang sangat bermanfaat. Dalam penerapan mengenai Diagnosa keperawatan sering kali pelaku masih mendapatkan hasil yang tidak memuaskan, hal tersebut biasa terjadi karena kurangnya pemahaman perawat mengenai diagnosa keperawatan. Agar pendiagnosaan keperawatan berjalan dengan baik perawat harus lah memperhatikan . Faktor faktor yang saat penting yang harus di lakukan untuk mendapatan diagnosa keperawatan adalah yang sesuai dengan masalah yang di kelukan oleh pasien dan pasien dapat mencapai kesehatan yang optimal dan tidak ada kesalahan dalam pelaksaanan penentuan diagnosa keperawatan. Agar tercapainya kesehatan yang optimal yang peroleh oleh pasien dan kepuasan pasien dalam perawatan yang ia depatkan sehingga perawat mendapatkan motivasi untuk menjadi perawat yang lebih profesional lagi dalam melakukan tugasnya sebagai perawat.

Setelah melakukan diagnosa keperawatan yang di lakukan perawat harus memperhatikan respon dari pasien baik respon positif maupun respon negatif yang di tunjukkan pada pasien pada saat pendiagnosaan setelah itu perawat harus melakukan evaluasi untuk mengetahui diagnosa keperawatan yang di lakukan sudah berjalan dengan baik atau malah gagal atau tidak berjalan dengan baik sesuai dengan perencanaan yang sudah di buat sebelumnya. Eveluasi sangan di butuhkan untuk menjadi pembanding atau bahkan menjadi penilaian saat menentukan apakah diagnosa keperawatan memberi pengaruh yang baik atau pun yang buruk.

Dalam melakukan diagnosa keperawatan ini sering kali perawat merasa bingung dalam menetukan diagnosa yang paling tepat hal ini di karenakan kuranya pengetahuan perawat atau ketidak perofesionalan perawat dalam melakukan tugasnya. Untuk itu perawat di minta untuk terus belajar untuk mendapatkan pemahaman yang paling tepat mengenai diagnosa keperawatan yang sesuai dengan masalah pasien. Untuk penentuan diagnosa keperawatan perawat juga harus berfikir keritis memiliki penalaran yang tinggi juga pengalama pengalaman yang tinggi. 


\section{Pembahasan}

Pengkajian merupakan langkah pertama dari proses keperawatan dengan kegiatan pengumpulan data, memvalidasi data pengorganisasian data dan mencatat data yang diperoleh. Langkah ini merupakan dasar untuk perumusan diagnosis keperawatan dan mengembanggkan rencana keperawatan sesuai kebutuhan pasien serta melakukan implementasi keperawatan (Abd Wahid \& Imam Suprapto, 2012) dan (Potter dan Perry, 2005).

Diagnosis keperawatan menggambarkan respon manusia pada diri pasien terhadap perubahan perubahan dalam dimensi bio-psiko-sosiospiritual. Diagnosis keperawatan dapat mengkomunikasikan kepada rekan sejawat atau tenaga kesehatan lainnya, dimana perawatan yang diberikan perawat kepada pasien berfokus pada kebutuhan individual pasien. Sebuah diagnosis keperawatan dapat berupa masalah kesehatan yang bersifat aktual yang secara klinis jelas atau masalah kesehatan potensial dimana faktor-faktor resiko dapat mengancam kesehatan pasien secara umum. Kedua jenis diagnosis keperawatan tersebut harus di intervensi untuk memecahkan masalah atau mengurangi atau mencegah timbulnya masalah (Sumijatun, 2009).

Diagnosa keperawatan adalah keputusan klinis mengenai seseorang, keluarga, atau masyarakat sebagai akibat dari masalah kesehatan atau proses kehidupan yang aktual atau potensial. Diagnosa keperawatan merupakan dasar dalam penyusunan rencana tindakan asuhan keperawatan.Diagnosis keperawatan sejalan dengan diagnosis medis sebab dalam mengumpulkan data-data saat melakukan pengkajian keperawatan yang dibutuhkan untuk menegakkan diagnosa keperawatan ditinjau dari keadaan penyakit dalam diagnosa medis.

Perumusan diagnosa keperawatan membutuhkan proses berpikir kritis, keterampilan penalaran dan pengalaman sebelumnya (Poortaghi et al. 2015). Penyusunan format diagnosa keperawatan standar yang sedang disusun oleh RS Dirgahayu saat ini menggunakan pendekatan standar NANDA. Tim penyusun terdiri dari kepala ruang, supervisor dan manajemen keperawatan dengan latar belakang pendidikan dan pengalaman kerja di bidang keperawatan. Perawat menyepakati bahwa tipe checklist mudah diaplikasikan jika format diagnosa keperawatan yang baru nanti tersusun. Checklist ini merupakan salah satu metode pengamatan terstruktur di mana sebelumnya secara cermat sudah mendefinisikan apa yang akan diobservasi melalui suatu perencanaan yang matang (Nursalam, 2013).

Diagnosis Keperawatan merupakan keputusan klinik tentang respon individu, keluarga dan masyarakat tentang masalah kesehatan aktual atau potensial, dimana berdasarkan pendidikan 
dan pengalamannya, perawat secara akuntabilitas dapat mengidentifikasi dan memberikan intervensi secara pasti untuk menjaga, menurunkan, membatasi, mencegah dan merubah status kesehatan klien (Yeni, 2008). Untuk dapat merumuskan diagnosa keperawatan dibutuhkan kemampuan analisis yang tinggi sehingga diperlukan sumber daya manusia yang capable dan mempunyai motivasi kuat untuk maju serta berpandangan maju (futuristic). Pada status pasien yang telah dikaji terlihat bahwa perawat hanya memilih saja diagnosa keperawatan yang telah disediakan di bagian samping format pengkajian. Hal ini memang lebih memudahkan perawat akan tetapi juga dapat menyebabkan perawat menjadi malas dan kurang inisiatif untuk menganalisa data lalu merumuskan diagnosa keperawatan sendiri apabila ditemukan data yang berbeda. Kondisi demikian juga menimbulkan kualitas pendokumentasian diagnosa keperawatan menjadi monoton (Hartati, Handoyo, Anis, 2010).

Diagnosis keperawatan yang ditegakkan berdasarkan pengkajian NANDA-ISDA lebih beragam daripada diagnosis keperawatan yang ditegakkan oleh perawat. Dengan NANDAISDA pengkajian dilakukan dari berbagai Aspek dan didasari pada pemahaman terhadap definisi suatu diagnosis tersebut (Nurjannah, 2010). Sedangkan diagnosis yang dibuat perawat tidak didasari pada pengkajian dan pemahaman tentang definisi diagnosis itu sendiri, contohnya terdapat diagnosis "Gangguan pola tidur". Istilah ini tidak ditemukan dalam nomenklatur NANDA-I, untuk data kurang tidur. Namun data " kurang tidur " akan memunculkan diagnosis "Risiko jatuh". Begitu pula, tidak satupun tidak satupun masalah kolaborasi (potensial complication) ditegakkan oleh perawat sementara dari rutinitas pekerjaan yang dilakukan lebih banyak pada pekerjaan mengatasi masalah pontensial komplikasi.

Diagnosa keperawatan ditegakkan berdasarkan respon fisik, sosio-kultural, psikologis, dan spiritual klien terhadap masalah kesehatannya yang bersifat individual, sehingga diperlukan kemampuan berpikir kritis dalam proses diagnostik. Penegakkan diagnosa keperawatan haruslah didukung sekelompok data dasar yang didapatkan oleh perawat saat melakukan pengkajian. Kelompok data ini disebut batasan karakteristik. Batasan karakteristik adalah indikator klinis yang merupakan tanda dan gejala objektif atau subjektif atau faktor risiko yang mendukung adanya kategori diagnostik. Indikator klinis yang akurat diperlukan untuk memvalidasi diagnosa keperawatan yang ditegakkan. Keakuratan indikator klinis ditentukan dengan kemunculan batasan karakteristik dan faktor yang berhubungan (etiologi) dari suatu diagnosa keperawatan. 
Diagnosis keperawatan dibuat berdasarkan hasil pengkajian yang dilakukan oleh perawat sesuai dengan apa yang tertuang pada format pengkajian. Diagnosis keperawatan aktual adalah diagnosis keperawatan yang menjelaskan masalah nyata yang ada pada saat pengkajian dilakukan. Diagnosis keperawatan potensial adalah diagnosis keperawatan yang menjelaskan masalah nyata yang akan terjadi jika tindakan keperawatan tidak dilakukan. Jadi masalahnya belum ada tapi penyebabnya sudah ada. Kekurangan dalam melakukan diagnosis keperawatan harus secepatnya dikoreksi karena akan menentukan dalam rencana tindakan sehingga pecapaian tujuan utama keperawatan akan mengalami hambatan (Patricia W Ilyer. Nancy $\mathrm{H}$ camp, 2001).

\section{Kategori Diagnosa Keperawatan}

Diagnosa keperawatan dapat dibedakan menjadi 5 kategori: (1) Aktual, (2) Resiko, (3) Kemungkinan, (4) Keperawatan welness, (5) Keperawatan Sindrom.

1. Aktual Diagnosa Keperawatan aktual menjelaskan masalah nyata saat ini sesuai dengan data klinik yang ditemukan.Syarat menegakkan diagnosa keperawatan aktual harus ada unsur PES.Symptom (S) harus memenuhi kriteria mayor dan sebagian kriteria minor dari pedoman diagnosa NANDA.

2. Risiko Diagnosa Keperawatan Risiko menjelaskan masalah kesehatan yang nyata akan terjadi jika tidak dilakukan intervensi. Syarat menegakkan risiko diagnosa keperawatan adanya unsur PE (problem dan etiologi).Penggunaan istilah "risiko dan risiko tinggi" tergantung dari tingkat keparahan/kerentanan terhadap masalah. Diagnosa: "Risiko gangguan integritas kulit berhubungan dengan diare yang terus menerus".

3. Kemungkinan Diagnosa Keperawatan Kemungkinan menjelaskan bahwa perlu adanya data tambahan untuk memastikan masalah keperawatan kemungkinan.Pada keadaan ini masalah dan faktor pendukung belum ada tapi sudah ada faktor yang dapat menimbulkan masalah.Syarat menegakkan kemungkinan diagnosa keperawatan adanya unsur respons (Problem) dan faktor yang mungkin dapat menimbulkan masalah tetapi belum ada.

4. Diagnosa Keperawatan "Wellness" Diagnosa keperawatan wellness (sejahtera) adalah keputusan klinik tentang keadaan individu, keluarga, dan atau masyarakat dalam transisi dari tingkat sejahtera tertentu ke tingkat sejahtera yang lebih tinggi. Ada 2 kunci yang harus ada:

1) Sesuatu yang menyenangkan pada tingkat kesejahteraan yang lebih tinggi 
2) Adanya status dan fungsi yang efektif.

Diagnosa keperawatan yang valid dapat membantu menyelesaikan masalah pasien, namun proses mengidentifikasi diagnosa keperawatan yang sesuai sangat sulit dilakukan karena respon manusia yang kompleks dan unik. Selain itu, diagnosa keperawatan yang valid sangat penting untuk mengurangi risiko kesalahan mendiagnosis. Kesalahan dalam menegakkan diagnosa keperawatan mengakibatkan perawat salah dalam menentukan tujuan serta intervensi yang berdampak pada tidak teratasinya masalah pasien, meningkatnya masa perawatan serta biaya perawatan dan risiko terjadinya komplikasi. Oleh karena itu, ketika melakukan penelitian mengenai diagnosa keperawatan harus berfokus pada keakuratan indikator klinis.

Pada prakteknya, perawat sering mengalami kesulitan dalam melaksanakan asuhan keperawatan. Sering sekali perawat kesulitan dalam hal menetapkan diagnosa keperawatan yang tepat bagi pasien. Pada kasus yang lain, data dikumpulkan tanpa menyadari mengenai apa diagnosanya?. Perawat juga mengumpulkan data yang mempunyai relevansi yang rendah dengan diagnosa keperawatan tertentu. Penelitian menunjukkan bahwa rendahnya keakuratan dalam diagnosa keperawatan berkaitan dengan banyaknya jumlah data yang relevansinya rendah (Nurjannah I, 2012).

Pengetahuan dan motivasi dari organisasi dapat menjadikan organisasi tersebut memahami tujuan keberadaannya. Motivasi individu merupakan faktor terpenting dalam peningkatan pendokumentasian asuhan keperawatan. Motivasi dipengaruhi oleh dua faktor yaitu faktor intrinsik dan faktor ekstrinsik. Faktor intrinsik meliputi prestasi, pengakuan diri, sifat pekerjaan tanggung jawab dan pengembangan karir sedangkan faktor ekstrinsik meliputi gaji, lingkungan kerja, hubungan kerja. Teori Herzberg juga menyampaikan bahwa kinerja dipengaruhi oleh faktor motivator yang dimanifestasikan pada keberhasilan, penghargaan, tanggung jawab, pekerjaan, dan pengembangan diri. Teori ini menjelaskan bahwa dengan perubahan intrinsik faktor kepuasan kerja dapat dimotivasi. Sedangkan faktor ekstrinsik hanya merupakan faktor yang bersifat pencegah terjadinya ketidakpuasan kerja (Ilyas,2002). Penerapan pengetahuan yang baik dan peningkatan motivasi perawat dalam pendokumentasian asuhan keperawatan menjadi solusi dalam meningkatkan kinerja pendokumentasian asuhan keperawatan untuk menyelesaikan masalah.

\section{Kesimpulan}

Pengkajian merupakan langkah pertama dari proses keperawatan dengan kegiatan pengumpulan data, memvalidasi data pengorganisasian data dan mencatat data yang diperoleh. 
Diagnosa keperawatan adalah keputusan klinis mengenai seseorang, keluarga, atau masyarakat sebagai akibat dari masalah kesehatan atau proses kehidupan yang aktual atau potensial. Diagnosis keperawatan yang ditegakkan berdasarkan pengkajian NANDA-ISDA lebih beragam daripada diagnosis keperawatan yang ditegakkan oleh perawat. Diagnosis keperawatan dibuat berdasarkan hasil pengkajian yang dilakukan oleh perawat sesuai dengan apa yang tertuang pada format pengkajian. Perumusan diagnosa keperawatan membutuhkan proses berpikir kritis, keterampilan penalaran dan pengalaman sebelumnya. Pada prakteknya, perawat sering mengalami kesulitan dalam melaksanakan asuhan keperawatan. Sering sekali perawat kesulitan dalam hal menetapkan diagnosa keperawatan yang tepat bagi pasien.

\section{Daftar putaka}

Apriyani. Heni. (2015). Identifikasi Diagnosa Keperawatan Pada Pasien di Ruang Paru Sebuah Rumah Sakit. Jurnal Keperawatan, 11(1), 107-111.

Cikwanto , Nupiyanti. (2018). Pengembangan Instrumen Penegakan Diagnosis Keperawatan

Pada Pasien Congestive Heart Failure (CHF) Berbasis Standar Diagnosis Keperawatan Indonesia (SDKI). Jurnal Keperawatan 'AISYIYAH, 5(1), 51-63.

Ermayani. Made, Aprilia Nuryanti. (2017). Pengenmangan Format Dokumentasi Asuhan Keperawatan berbasis Atandarized Nursing Language (SNL) NANDA-I, NOC dan NIC di Ruang Rawat Inap. Mahakam Nursing Journal, 2(2), 50-61

Kusnadi. Elon. (2017). Analisis Kelengkapan Dokumentasi Keperawatan di Ruang Rawat Inap Non Intensive Rumah Sakit X. Jurnal Bidang Ilmu Kesehatan, 9(1), 553-561.

Mulyanti.Yuli dan Dinarti . 2017. Dokumentasi keperawatan, jakarta: Kementrian Kesehatan Republik Indonesia

Nursalam. (2013). Metodologi penelitian ilmu keperawatan; pendekatan praktis, edisi 3, Penerbit Salemba Medika, Jakarta Selatan.

Rofi Muhamad (dkk). (2018). Diagnosa Keperawatan Yang Sering Ditegakkan Perawat Pada Pasien Tuberkulosis Paru Di Rumah Sakit. Jurnal Kepemimpinan dan Manajemen Keperawatan, 1(2), 1-8.

Santoso. R. Arief. (2018). Hubungan Pengetahuan dan Motivasi Perawat Dengan Kinerja Pendokumentasian Asuhan Keperawatan di Pelayanan Rawat Inap Puskesmas Guluk Guluk .Jurnal Ilmu Kesehatan, 3(1), 10-19. 
Sari. Selvia Harum , Agianto , Abdurahman Wahid. (2015), Batasan Karakteristik dan Faktor yang Berhubungan (Etiologi) Diagnosa Keperawatan: Hambatan Mobilitas Fisik Pada Pasien Stroke, Jurnal Batasan Karakteristik dan Etiolog, 3(1), 12-21

Simamora, R. H., Bukit, E., Purba, J. M., \& Siahaan, J. (2017). Penguatan kinerja perawat dalam pemberian asuhan keperawatan melalui pelatihan ronde keperawatan di rumah sakit royal prima medan. Jurnal pengabdian kepada masyarakat, 23(2), 300-304.

Simamora, R. H. (2019). Socialization of Information Technology Utilization and Knowledge of Information System Effectiveness at Hospital Nurses in Medan, North Sumatra. Editorial Preface From the Desk of Managing Editor..., 10(9).

Supratti , Ashriady. (2016). Pendokumentasian Standar Asuhan Keperawatan di Rumah Sakit Umum Daerah Mamuju,Insonesia. Jurnal Kesehatan MANARANG, 2(1), 44-51. 